


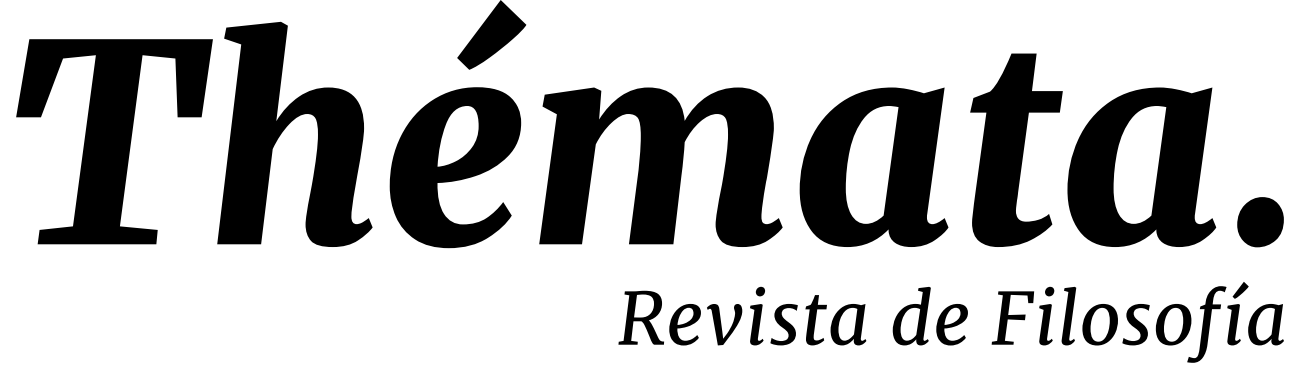

\section{La transmisión filosófica. Pensamiento de Javier Hernández-Pacheco Sanz}

Alejandro Martín Navarro (Coord.)

ESPECIAL THÉMATA

2022

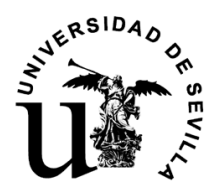

ISSN 0212-8365

e-ISSN 2253-900X

DOI: $10.12795 /$ themata

revistascientificas.us.es/index.php/themata

https://editorial.us.es/es/revistas/themata-revista-de-filosofia 
Thémata. Revista de Filosofía.

Número Extra

Thémata. Revista de Filosofía nace en el año 1983 con la intención de proporcionar a quienes investigan y producen en filosofía un cauce para publicar sus trabajos y fomentar un diálogo abierto sin condicionamientos ideológicos. En sus inicios participaron en el proyecto las Universidades de Murcia, Málaga y Sevilla, pero pronto quedaron como gestores de la revista un grupo de docentes de la Facultad de Filosofía de la Universidad de Sevilla.

Una preocupación constante de sus realizadores ha sido fomentar los planteamientos interdisciplinares. La revista ha estado abierta siempre a colaboradores de todas las latitudes y ha cubierto toda la gama del espectro filosófico, de lo que constituye una buena prueba la extensa nómina de autores que han publicado en sus páginas. En sus páginas pueden encontrarse trabajos de todas las disciplinas filosóficas: Historia de la Filosofía, Metafísica, Gnoseología, Epistemología, Lógica, Ética, Estética, Filosofía Política, Filosofía del Lenguaje, Filosofía de la Mente, Filosofía de la Ciencia, Filosofía de la Historia, Filosofía de la Cultura, etc. También ha querido ser muy flexible a la hora de acoger nuevos proyectos, fomentar discusiones sobre temas controvertidos y abrirse a nuevos valores filosóficos. Por esta razón, los investigadores jóvenes siempre han encontrado bien abiertas las puertas de la revista.

\section{Equipo editorial / Editorial Team Bases de Datos y Repertorios}

Director honorario

Jacinto Choza Armenta

jchoza@us.es

Director

Fernando Infante del Rosal

finfante@us.es

Director Adjunto

José Manuel Sánchez López

themata@us.es

Subdirectores

Jesús Navarro Reyes

jnr@us.es

Inmaculada Murcia Serrano

imurcia@us.es

Jesús de Garay

jgaray@us.es

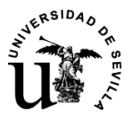

Facultad de Filosofía. Universidad de Sevilla

Departamento de Estética e Historia de la

Filosofía

Departamento de Filosofía y Lógica y Filosofía

de la Ciencia

Departamento de Metafísica y Corrientes

Actuales de la Filosofía, Ética y Filosofía Política

Camilo José Cela s/n, 41018 Sevilla (España)

e-mail: themata@us.es
Bibliográficas internacionales

Emerging Sources Citation Index (Web of

Science Group-Clarivate Analytics)

Dialnet (España)

Francis, Philosophie. INIST-CNRS (France)

Philosopher's Index (Bowling Green, OH, USA)

Directory of Open Access Journals (DOAJ)

Repertoire Bibliographique de Philosophie

(Louvain, Belgique)

Ulrich's Internacional Periodicals Directory

(New York, USA)

DialogJournalNameFinder (Palo Alto, CA, USA)

Periodicals Index Online (Michigan, USA)

Index Copernicus World of Journals

Gale-Cengage Learning-Informe Académico

Academic Journal Database

DULCINEA

Google Scholar

Electra

Bulletin signaletique. Philosophie, CNRS

(France)

Bibliográficas nacionales

ISOC - Filosofía. CINDOC (España)

De evaluación de la calidad de revistas

CARHUS Plus

ERIH PLUS Philosophy (2016)

REDIB

Latindex 2.0

MIAR

CIRC

DICE

Política editorial y directrices para autores/as, al final de la revista.

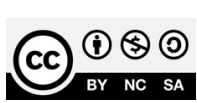


Thémata. Revista de Filosofía.

\section{Consejo Editor / Editorial Board}

\section{ARGENTINA}

Flavia Dezzuto, Universidad Nacional de Córdoba

ALEMANIA

Alberto Ciria, Munich

\section{CANADÁ}

Óscar Moro, University of New Found Land

CHILE

Mariano De la Maza, Universidad Católica de Chile

José Santos Herceg, Universidad de Santiago de Chile

\section{COLOMBIA}

Martha Cecilia Betancur García, Universidad de Caldas

Víctor Hugo Gómez Yepes, Universidad Pontificia Bolivariana

Gustavo Adolfo Muñoz Marín, Universidad Pontificia Bolivariana

\section{ESPAÑA}

Alfonso García Marqués, Universidad de Murcia

Antonio De Diego González, Universidad de Sevilla

Avelina Cecilia Lafuente, Universidad de Sevilla

Carlos Ortiz Landázuri, Universidad de Navarra

Celso Sánchez Capdequí, Universidad Pública de Navarra

Elena Ronzón Fernández, Universidad de Oviedo

Enrique Anrubia, Universidad CEU Cardenal Herrera

Federico Basáñez, Universidad de Sevilla

Fernando Wulff, Universidad de Málaga

Fernando M. Pérez Herranz, Universidad de Alicante

Fernando Pérez-Borbujo, Universitat Pompeu Fabra

Francisco Rodríguez Valls, Universidad de Sevilla

Ildefonso Murillo, Universidad Pontificia de Salamanca

Irene Comins Mingol, Universitat Jaume I Jacinto Rivera de Rosales Chacón, † UNED Joan B. Llinares, Universitat de València Jorge Ayala, Universidad de Zaragoza José Manuel Chillón Lorenzo, Universidad de Valladolid
Juan García González, Universidad de Málaga

Juan José Padial Benticuaga, Universidad de Málaga

Luis Miguel Arroyo Arrayás, Universidad de Huelva

Ma Luz Pintos Peñaranda, Universidad de Santiago de Compostela

Marcelo López Cambronero, Instituto de Filosofía Edith Stein

María del Carmen Paredes, Universidad de Salamanca

Octavi Piulats Riu, Universitat de Barcelona

Óscar Barroso Fernández, Universidad de Granada

Pedro Jesús Teruel, Universitat de València

Ramón Román Alcalá, Universidad de Córdoba

Ricardo Parellada, Universidad Complutense de Madrid

Sonia París Albert, Universitat Jaume I

Tomás Domingo Moratalla, UNED

\section{ESTADOS UNIDOS}

Witold Wolny, University of Virginia)

Thao Theresa Phuong Phan, University of Maryland

\section{REINO UNIDO}

Beatriz Caballero Rodríguez, University of Strathclyde

ITALIA

Luigi Bonanate, Università di Torino

\section{MÉXICO}

Rafael De Gasperín, Instituto Tecnológico de Monterrey

Julio Quesada, Universidad Veracruzana

Adriana Rodríguez Barraza, Universidad Veracruzana

PERÚ

Ananí Gutiérrez Aguilar, Universidad Nacional de San Agustín de Arequipa y Universidad Católica de Santa María

Nicanor Wong Ortiz, Universidad San Ignacio de Loyola

\section{PORTUGAL}

Yolanda Espiña, Universidade Católica Portuguesa

\section{TURQUÍA}

Mehmet Özkan, SETA Foundation for Political, Economic and Social Research 
Thémata. Revista de Filosofía.

\section{Comité Científico Asesor / Advisory Board}

ARGENTINA

Graciela Maturo, Universidad de Buenos Aires - CONICET

Jaime Peire, Universidad Nacional de Tres de Febrero- CONICET

\section{ALEMANIA}

Tomás Gil, Freie Universität Berlin

Fernando Inciarte, $\dagger$ Westfälische WilhelmsUniversität

Otto Saame, † Universität Mainz

\section{BULGARIA}

Lazar Koprinarov, South-West University 'Neofit Rilski'

CHILE

Carla Corduá, Universidad de Chile

Roberto Torreti, Universidad de Chile

COLOMBIA

Carlos Másmela, Universidad de Antioquía Fernando Zalamea, Universidad Nacional de Colombia

\section{ESPAÑA}

Agustín González Gallego, Universitat de Barcelona

Alejandro Llano, Universidad de Navarra Andrés Ortiz-Osés, Universidad de Deusto Ángel D'ors, † Universidad Complutense de Madrid

Antonio Hermosa Andújar, Universidad de Sevilla

Carlos Beorlegui Rodríguez, Universidad de Deusto

Concha Roldán Panadero, Instituto de Filosofía, CCHS-CSIC

Daniel Innerarity Grau, Ikerbasque, Basque Foundation for Science

Francisco Soler, Universidad de Sevilla Ignacio Falgueras, Universidad de Málaga Javier San Martín, UNED

Jesús Arellano Catalán, † Universidad de Sevilla

Joaquín Lomba Fuentes, Universidad de Zaragoza

Jorge Vicente Arregui, † Universidad de Málaga José María Prieto Soler, † Universidad de Sevilla José Rubio, Universidad de Málaga Juan Antonio Estrada Díaz, Universidad de Granada

Juan Arana Cañedo-Argüelles, Universidad de Sevilla
Luis Girón, Universidad Complutense de Madrid

Manuel Fontán Del Junco, Fundación March

Manuel Jiménez Redondo, Universitat de València

Marcelino Rodríguez Donís, Universidad de Sevilla

Miguel García-Baró López, Universidad Pontificia Comillas

Modesto Berciano, Universidad de Oviedo

Pascual Martínez-Freire, Universidad de Málaga

Rafael Alvira, Universidad de Navarra

Teresa Bejarano Fernández, Universidad de Sevilla

Vicente San Félix Vidarte, Universitat de València

\section{ESTADOS UNIDOS}

Lawrence Cahoone, University of Boston

FRANCIA

Nicolás Grimaldi, Université Paris IV-Sorbonne

\section{PARAGUAY}

Mario Ramos Reyes, Universidad Católica de Asunción

\section{REINO UNIDO}

Alexander Broadie, University of Glasgow

ISRAEL

Marcelo Dascal, † Tel Aviv University

ITALIA

Massimo Campanini, Università di Napoli l'Orientale

Maurizio Pagano, Università degli Studi del Piamonte Orientale. Amedeo Avogadro

JAPóN

Juan Masiá, Sophia University, Tokio

\section{MÉXICO}

Jaime Méndez Jiménez, Universidad Veracruzana

Ana Laura Santamaría, Instituto Tecnológico de Monterrey

Héctor Zagal, Universidad Panamericana

VENEZUELA

Seny Hernández Ledezma, Universidad Central de Venezuela

Thémata. Revista de Filosofía agradece la labor realizada desde su inicio por sus anteriores directores: Jacinto Choza, Juan Arana y Jesús de Garay. 


\section{Índice.}

\section{LA TRANSMISIÓN FILOSÓFICA. PENSAMIENTO DE JAVIER HERNÁNDEZ-}

PACHECO SANZ_ESPECIAL THÉMATA

9 El acto filosófico. En recuerdo de Javier Hernández-Pacheco Sanz Fernando Infante del Rosal

14 Presentación

Alejandro Martín Navarro (Coord.)

SEMBLANZAS Y RECUERDOS_JAVIER HERNÁNDEZ-PACHECO SANZ,

TRANSMISIÓN Y ENSEÑANZA DE LA FILOSOFÍA

19 Treinta y siete años con Pacheco. Variaciones sobre el cristianismo Jacinto Choza Armenta

$51 \quad$ Historia de un hombre sabio y bueno Juan Arana Cañedo-Argüelles

$54 \quad$ Una fuerza de la naturaleza José Manuel Sánchez López

58 In Memoriam a Javier Hernández-Pacheco Urbano Ferrer Santos

65 Recordando al profesor Javier Hernández-Pacheco Esperanza María Domínguez Sabido

OBRA Y PENSAMIENTO DE JAVIER HERNÁNDEZ-PACHECO SANZ_ARTÍCULOS

$71 \quad$ Una conversación pendiente Jesús de Garay Suárez-Llanos

87 Un viaje de ida y vuelta: de cómo el refugio se torna apertura. El proyectar(se) como apertura a lo Otro Elisa Fernández Bascones

107 Max Horkheimer y el anhelo de lo completamente Otro. (A propósito de la interpretación de la filosofía de Max Horkheimer de Javier Hernández-Pacheco) José Manuel Panea Márquez 
Thémata. Revista de Filosofía.

124 Javier Hernández-Pacheco: fe y filosofía

Lidia Romero Sánchez

$141 \quad$ La plenitud hacia la que tendemos: historia de una discusión truncada.

Francisco José Soler Gil

161 Tábula gratulatoria.

163 Política editorial.

166 Directrices para autores/as.

ILUSTRACIÓN DE CUBIERTA: Javier Infante 
Thémata. Revista de Filosofía.
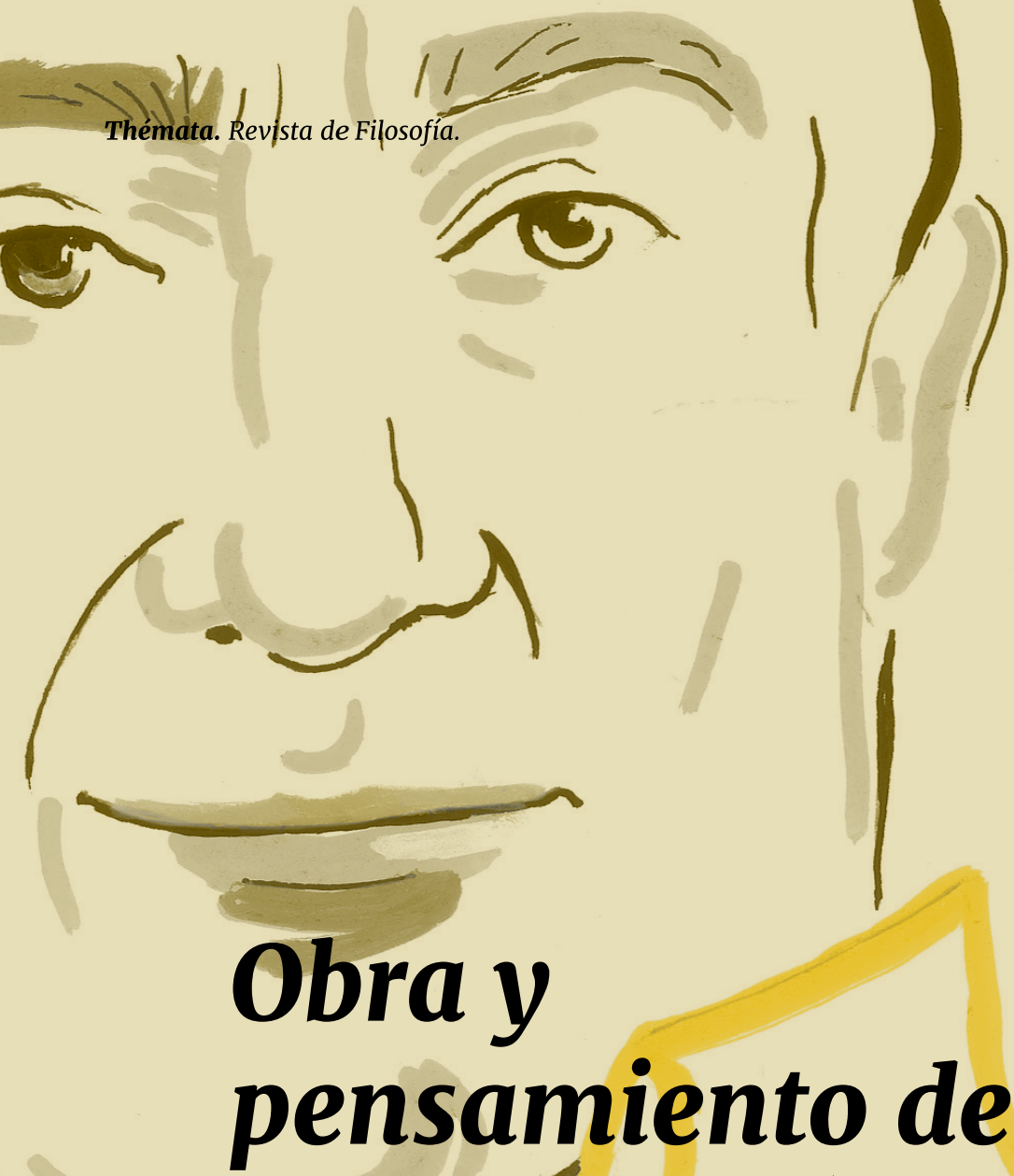

Javier HernándezPacheco Sanz. 


\title{
Javier Hernández-Pacheco: fe y filosofía.
}

Javier Hernández-Pacheco:

fe y filosofía.

\author{
Lidia Romero Sánchez' \\ Universidad de Sevilla, España \\ Recibido 15 mayo 2021 · Aceptado 1 diciembre 2021
}

\section{Resumen}

En este artículo pretendo acercar al lector a una parte del pensamiento de Javier Hernández-Pacheco, el del filósofo de los últimos años.

Es muy interesante la visión que nuestro autor tenía del cristianismo, más concretamente de los Dogmas de la Iglesia católica y del Evangelio. A través de su mirada, pasamos por cómo entiende él el Paraíso, el pecado (y el pecador), la resurrección, y llegamos de vuelta al Paraíso. Palabras clave: Javier Hernández-Pacheco, cristianismo, resurrección, mito, paraíso

\section{Abstract}

This article pretend that the reader has a closer look to thinking of Javier Hernández-Pacheco, the philosopher of the last few years.

He has a very interesting vision about Christianity, specifically The Catholic Church Dogma and the Gospel. Through his view, we go from how he understands the Paradise, sin (and sinner), resurrection, and we go back to Paradise.

Keywords: Javier Hernández-Pacheco, Christianity, resurrection, myth, Paradise

\section{1・Introducción}

Conocí a Javier Hernández-Pacheco Sanz en mi tercer año en la Facultad de Filosofía de Sevilla, allá por el año 2000, cuando impartió una de las asignaturas de aquel curso. Lo que más me llamó la atención sobre él 
fue su carácter, siempre afable, sencillez y carisma. Me atrevería a decir que rápidamente fui consciente de que era un profesor bueno, a la vez de ser un buen profesor.

Leí su libro La Conciencia Romántica, recomendado por una amiga, la cual había estado en su clase el año anterior, se había enamorado de su obra y de su forma de ser. Este libro se convirtió en mi favorito, hasta el punto de que me lo llevé a Alemania cuando fui de Erasmus, consideraba que debía ser lectura obligatoria. Ese ejemplar se lo regalé a una amiga argentina antes de marcharme, ella aún lo tiene. Yo conseguí otro ejemplar unos años más tarde y ya no me volví a separar de él, en mis mudanzas y en mis traslados transoceánicos.

Hasta su fallecimiento siempre lo llamé de "usted", a pesar de que él siempre insistía para que lo tutease, era tanto el respeto y la admiración que le tenía (y tengo) que no concebía llamarlo de otra manera. Ahora lo llamaré "Javier" porque él así lo quería.

Volví a retomar el contacto con Javier, una vez terminada mi licenciatura, cuando le pedí que dirigiese mi tesis, Antisemitismo y Crítica a la Modernidad. Después de tantos años, y seguramente sin acordarse de quién era yo, me dijo rápidamente que sería el director de mi tesis. En un principio quería enfocar mi estudio en Hannah Arendt, pero tras hablar con él, y siempre teniendo en cuenta cómo quería llevar mi investigación, abrí mi trabajó al pensamiento de Max Horkheimer, de quien Javier era gran conocedor, así como de los demás miembros de la Escuela de Frankfurt.

En mi discurso ante el tribunal de defensa le di las gracias, también se las di por escrito en mi tesis en el apartado de "Agradecimientos", pero creo que él nunca fue consciente de la magnitud de mi agradecimiento, porque tengo claro que sin su ayuda y su gran paciencia, nunca lo hubiera conseguido. Siempre tuvo palabras de aliento y nunca me dejó abandonar el proyecto.

Aquí voy a hablar de su obra ¿Alguien Entiende a Dios?. Mi elección puede sorprender, dado que he expresado que la Conciencia Romántica es mi libro favorito. ¿Por qué entonces hablar del primero y no del segundo?. Creo que todos aquellos que conocían a Javier pueden entender mi elección y, para todos aquellos que lo estén empezando a conocer a través de estos artículos, espero que puedan conocer, no sólo al filósofo, también al profesor. En 
palabras de Javier: "Así que me propongo en estas páginas ejercer esa autonomía intelectual para presentar mis reflexiones sobre lo que considero el sentido 'auténtico' del cristianismo" 2 .

Dado lo extenso de esta obra, me voy a centrar principalmente en el cuarto capítulo: Creo en Jesucristo, su Único Hijo, y, sobre todo, en el sexto apartado: Padeció bajo el poder de Poncio Pilatos, fue crucificado...También voy a hacer un breve estudio de los apartados titulados: Y al Tercer Día resucitó, y Subió a los Cielos, y Desde Allí ha de Venir a Juzgar a Vivos y a Muertos.

Considero que tales apartados son esenciales a la hora de entender el pensamiento de nuestro autor a la hora de unir fe y filosofía. HernándezPacheco era un filósofo nato, y como educador estaba entre los mejores. Pero pocos saben su unión con el cristianismo, y más concretamente con el catolicismo, del que era conocedor, pero que él mismo reconocía que le quedaba mucho por aprender, ahí vemos lo humilde que era y el afán por seguir conociendo que siempre tuvo, sapere aude.

Espero que con esta pequeña contribución por mi parte a dar a conocer el pensamiento de Hernández-Pacheco, se haga honor a su obra y su legado. Él, que fue un buen hombre y un buen profesor, también se merece el reconocimiento del mundo académico por su gran labor a la filosofía, a la que amó y con la que mantuvo un diálogo constante.

Por supuesto que la filosofía es necesaria; pero la están haciendo desde su ámbito propio los teólogos, juristas, sociólogos, antropólogos y economistas, incluso periodistas, en la medida en que esos saberes y discursos reflexionan sobre sus propios fundamentos. La filosofía que todavía importa tiene actualmente la forma de una serie inconexa de meta-teorías, por supuesto despreciadas por los filósofos profesionales. Y así, no solamente fracasó en su antigua meta de realizar la unidad de los saberes, sino que ni siquiera puede garantizar la propia. ${ }^{3}$

2 Hernández-Pacheco, Javier (2017). ¿Alguien Entiende a Dios?. Reflexiones Sobre el Catecismo de un Profesor de Filosofía. Madrid: Sekotia, p. 12.

3 Hernández-Pacheco, Javier. Usted Primero. Filosofía de las Buenas Maneras. Madrid: Marova, 2019, p. 10. 


\section{2 - Jesucristo, crucificado por el pecado del hombre}

En Cur Deus Homo, 4 San Anselmo de Canterbury nos cuenta la doctrina del fruto de la salvación del amor de Dios, el Padre, por el hombre y la obediencia del Hijo a su Padre para salvar al hombre, que, según San Anselmo, era la única manera de ser salvado. Con la muerte de Cristo se restablece la justicia, la cual había sido desviada por el pecado original. Con esto se entienda que, al ser Dios infinito, tan sólo una víctima infinita puede subsanar lo que ha sido destruido a través del pecado. Además, Anselmo afirma que el heroísmo del sacrificio de Jesucristo salda el pecado de carácter infinito, de esta manera, el hombre logra la salvación.

Hernández-Pacheco nos cuenta que este mismo argumento está implícito en San Pablo y en la patrística. ${ }^{5}$ Al ser Jesucristo hijo de Dios su naturaleza es divina $\mathrm{y}$, por lo tanto, infinita; esto conlleva a que todos sus actos adquieran la condición de ser tan infinitos como su persona.

Nuestro autor además afirma que él cree este hecho como cierto, es decir, cree que Jesucristo murió para restablecer la justicia rota por el pecado; pero, a diferencia de San Anselmo, opina que el pecado no es un daño directo a Dios, es decir, el pecado es Dios siendo vulnerable. Partiendo de este argumento, se llega a la conclusión de que la reconciliación difiere de la reparación de esa esencia de Dios que ha quedado dañada por el pecado del hombre.

Hernández-Pacheco dice también que "nosotros tenemos que, o al menos tendemos a, pensar a Dios a imagen de nuestra voluntad de poder, esto es, de nuestros pecados" ${ }^{6}$ Es decir, al más puro estilo nietzscheano,

4 La traducción al castellano es ¿Por qué Dios se hizo hombre?, es un libro que San Anselmo escribió en el período entre 1095 y 1098, siendo ya nuestro autor arzobispo de Canterbury.

5 La patrística es el estudio del cristianismo de los primeros siglos y de los padres de la Iglesia. Se considera que su periodo de observación abarca desde la parte final del Nuevo Testamento, concretamente desde los Hechos de los Apóstoles (año 100 DC) y hasta El Concilio de Calcedonia (451 DC), o hasta el Segundo Concilio de Nicea, del siglo VIII.

6 Hernández-Pacheco, Javier (2017). ¿Alguien Entiende a Dios?. Reflexiones Sobre el Cate- 
considerada esta voluntad de poder como el motor principal del hombre: el anhelo de lograr sus deseos, la manifestación de fuerza que lo hace mostrarse al mundo y, así, estar en el lugar que siente que le toca. Pensar a Dios de esta manera se debe a que, al principio del cristianismo, Dios y los sacrificios estaban unidos, no se concibe una cosa sin la otra. Los griegos y los babilonios eran conocidos, entre otras muchas cosas, por su capacidad de ofrecer sacrificios. En el judaísmo se hacían constantes sacrificios a Dios, estos constaban de animales, vegetales o incienso, los cuales eran sacrificados cada día en el Templo por los sacerdotes; la ley, que había de ser seguida, ordenaba que debían ofrecerse los primeros frutos de la tierra y los primeros animales nacidos. Cuando el Segundo Templo fue destruido por los romanos (70 d. C.), los sacrificios de animales cesaron.

Con la muerte de Jesucristo en la cruz, se ofreció el sacrificio por antonomasia, el mismo hijo de Dios, a la vez humano y divino, moría para restablecer esa justicia, como ya he mencionado. Por eso, al principio del cristianismo se hacia difícil romper con este Dios de los sacrificios, es decir, con un Dios justiciero e incluso vengativo si el hombre pecaba. Según Hernández-Pacheco, estas cualidades que se le atribuyen a Dios no le pertenecen, son más bien las cualidades inherentes al propio ser humano que, al saberse hecho a imagen y semejanza de Él, le transfiere su propio carácter.

Dios no mata a las personas, Dios tampoco mandó a su hijo a la muerte. Los humanos somos los que, con nuestras acciones y decisiones, provocamos esos hechos. De esta manera, con el Holocausto, por ejemplo, Dios no decidió mandar a seis millones de judíos a una muerte terrible, para hacerles pagar por sus pecados, más bien fue decisión de muchos hombres: empezando por Hitler y terminando con el alemán de a pie, antisemita pasivo, quien, con sus hechos, no sólo no puso fin a la locura, sino que los alentó. Los acontecimientos que le suceden a los hombres tras la creación no es culpa de Dios, sino es el resultado de esa voluntad pervertida y, por consiguiente, no afecta al Creador.

De la misma manera, Dios no mandó a su hijo a la muerte. Poncio Pilatos lo hizo, junto con aquellos hombres que gritaban por su ejecución, etc. De aquí se puede llegar a la conclusión de que fue por su propia misericordia 
por la que Jesús murió en la cruz, y no por una demanda de justicia. La muerte de su hijo no era necesaria para Dios, ni un requisito para la salvación.

\section{Dónde comienza el pecado y termina el pecador}

Hernández-Pacheco afirma que, cuando alguien inflige un mal a otra persona, tendemos a pensar que esa persona que ha producido ese mal es "mala". El problema está en que el pecado viene anteriormente. Volviendo al ejemplo del Holocausto, podemos decir que Hitler es malo, y no nos faltaría razón ante tal afirmación, Hitler es el pecador; pero el pecado viene antes, es el antisemitismo inherente en la sociedad europea.

Creo que esto se puede ver en el libro Eichmann en Jerusalén: Un Estudio Sobre la Banalidad del Mal de Hannah Arendt. Eichmann, fue el responsable de la "solución final" y de la trasportación de los judíos a los campos de concentración, por ello se puede llegar a afirmar que Eichmann era un "hombre malo", si no nos paramos a estudiar lo que Eichmann tenía detrás.

En todo momento Eichmann afirmó que era inocente de haber cometido cualquier crimen, sólo había obedecido órdenes, como lo hubiera hecho cualquier ciudadano respetuoso de la ley. Arendt quiso estudiar a Eichmann como persona, ya que, para ella, con el juicio en Jerusalén se abrió la puerta para cuestionar a Eichmann como un ser humano que ha cometido actos brutales contra otros seres humanos. Eichmann fue condenado por sus actos antes incluso de que empezara el juicio. Parece ser que Eichmann era capaz de mantener una buena conciencia porque había puesto en los otros su capacidad moral, el principio del imperativo de acción de Eichmann se basaba ahora en la ley del Führer. Con ello Eichmann se aseguró de tener una buena conciencia a pesar de no seguir con el imperativo moral de Kant, de quien era conocedor y llegó a decir que regía su vida a través del Imperativo Categórico, entregándose a los deberes del partido Nazi. Como sacrificio por la lealtad y deberes hacia el partido dejaba de ser ahora el gobernante de su propia vida. Para él era un idealista, ya que vivió por sus ideas y lo sacrificó todo por ellas, no dejaba que sus sentimientos y emociones se pusieran por medio de sus acciones, a pesar de que esto significaba lleva a los judíos a su muerte. Pero Eichmann nunca hubiera llegado a ser el responsable de la 
"solución final" si no hubiera sido un antisemita, aunque él pensara que no lo era, criándose en un ambiente en el que estaba establecido el antisemitismo y era incluso aceptado ampliamente, hasta el punto de no ser consciente de este hecho. Eichmann tampoco podría haber llevado a los judíos hasta la muerte si no hubiera tenido una maquinaria detrás que le sirviera de soporte, seguramente, sin esa maquinaria, Eichmann hubiera acabado siendo un antisemita pasivo y nunca hubiera llegado a más. Tuvo que haber muchos Eichmann, en mayores o menores puestos en el partido nazi y mezclados en la población alemana, para que el Holocausto se produjese. La historia de Eichmann es la historia de otros muchos alemanes que, por un motivo u otro, participaron activa o pasivamente en el asesinato contra los judíos.

Dios nos dio libre albedrío, este es la potestad que el ser humano tiene de obrar según considere y elija, es decir, Dios nos dio la capacidad de elección. Esto quiere decir que los seres humanos tenemos adquiridas naturalmente la libertad para tomar nuestras propias decisiones; pero nuestro entorno social, cultural e histórico puede hacer que nuestras tendencias hacia determinadas decisiones varíen. Es por todo ello que el ser humano, cuando decide hacer un mal, esta acción es el cúmulo de todo lo que le rodea, y sólo él y su circunstancia han de ser culpados. No se debe culpar a Dios por las acciones de los humanos, al fin y al cabo, ya lo dijo Ortega y Gasset, "yo soy yo y mi circunstancia".7

El existencialismo une la noción de libertad, la capacidad de tomar mis decisiones, con el concepto de angustia. Kierkegaard argumenta que el universo es fundamentalmente paradójico, y la paradoja principal es la unión transcendental de Dios y lo humano en la figura de Jesucristo. Kierkegaard propone que cada uno debe tomar decisiones independientes, las cuales constituyen su existencia. La angustia está en todos nosotros, es una angustia por indecisión, y permanece hasta que nos comprometemos con una decisión particular. Kierkegaard se situaba dentro de la religión protestante, pero otro famoso existencialista cristiano es el francés Gabriel Marcel, el cual procesaba la religión católica, y era un oponente el existencialismo ateo. Para Marcel la libertad es algo negativo y positivo a la vez; en su vertiente negativa, la libertad es la ausencia de lo que parece la alienación desde uno mismo;

7 En 1914, Ortega y Gasset acuñó esta frase en su libro, Meditaciones del Quijote. 
la libertad es positiva cuando los motivos de mi acción están dentro de los límites que considero que son estructuralmente características de mí mismo. Para Marcel, la libertad es siempre la posibilidad del yo, siempre dentro de los confines de las relaciones con los otros. Como existencialista, la libertad está sujeta a las experiencias del cuerpo, pero para él, además, la libertad es algo que debe vivirse a través de la experiencia, y el yo es totalmente libre cuando se sumerge en las posibilidades del yo y de las necesidades de los otros. Los hombres tienen una libertad básica y autónoma, pero sólo esas personas que buscan la experiencia de interactuar con otros hombres libres pueden romper la facticidad del cuerpo e introducirse en la satisfacción de ser.

Hernández-Pacheco nos habla de dónde sitúan el mal diversos pensadores. Hobbes y Schopenhauer afirman que es la naturaleza la que es mala, Rousseau y Max dicen que el mal se encuentra en la cultura hipercivilizada. Horkheimer y Adorno, sin embargo, declaran que el mal está en el poder que ejercemos sobre la naturaleza y la sociedad. La Biblia, sin embargo, no admite una perspectiva singular sobre el mal. La Biblia opera dentro de un entorno moral y espiritual en lugar de dentro de un entorno racionalista, abstracto, ontológico. Hay, básicamente, cuatro representaciones del mal en ella: caos, pecado, fuerzas demoníacas y sufrimiento. Por ejemplo, en el Génesis se dice que la creación de Dios es "buena", el mal es representado como entrando en la creación como consecuencia de la elección del hombre, Eva y Adán comiendo el fruto del árbol prohibido. Hernández-Pacheco afirma que manifestaciones de ese mal cósmico libremente querido por todos es lo que mató a Jesucristo. "En esa cruz obtenemos la medida de una tragedia, que es la del mundo, y la de cada uno de nosotros, que a su imagen fuimos creados, imagen de la que ahora somos la infinita perversión". ${ }^{8}$

Pero el judaísmo cree en la idea de un Dios omnipresente, justo y misericordioso. En el judaísmo no existe una doctrina del pecado como en el cristianismo. De hecho, la palabra pecado no aparece en el libro Bereshit (Génesis) en la historia de Adam, a diferencia de la interpretación que le dan los cristianos. Los cristianos interpretan la acción de Adán como un pecado que se traspasa al resto de la humanidad aún no nacida. El judaísmo, sin embargo, utiliza el concepto de teshuvá (el arrepentimiento). Por lo tanto, el judaísmo se pregunta cómo el hombre puede superar su tendencia a hacer el

8 Ibid. 135. 
mal, el cristianismo se pregunta cómo superar el pecado original.

En el texto no aparece la palabra pecado, podemos interpretarlo como que Adán y Eva eran inocentes y perdieron su inocencia. No se puede sacar la conclusión de que fuera una acción pecaminosa, una cosa es la desobediencia y otra cometer una maldad. En la Torá se utiliza el adjetivo "maldito", pero con él se califica a la serpiente y no Adán ni de Eva. La maldad conlleva hacer un daño, ya sea tanto físico como emocional, a sabiendas. El Dios de los judíos castiga según la magnitud del agravio.

La primera vez que aparece el mal en la Torá es en su forma extrema, en el asesinato del Abel por parte de su hermano Caín, también es la primera vez que se hace referencia a palabra "pecado". El pecado en la historia de los dos hermanos está delimitado a una tentación para el mal, que el hombre puede dominar, hay esperanza. No sabemos, leyendo la Torá, por qué Dios crea el hombre con la inclinación al mal. No hay un mal inherente en el universo, sino que el mal es parte integral de la naturaleza del hombre, y sólo a través de las enseñanzas y lo la disciplina el hombre es capaz de luchar contra él.

La respuesta del judaísmo para que dominemos esta inclinación al mal está en la entrega de las leyes. Con la obediencia a las leyes y a sus prácticas, el hombre será capaz de controlar lo que le lleva a hacer el mal. El judaísmo quiere que nos hagamos responsables de nuestras actitudes. Abraham Yoshua Heschel, rabino admirado dentro de la comunidad judía por su contribuciones y enseñanzas, decía que en la sociedad en la que vivimos, aunque algunos sean culpables, todos somos responsables, afirmación que Hernández-Pacheco también hacía, todos somos responsables de las acciones que se cometan contra los otros si no hacemos nada.

Al ser el mal parte inherente de la naturaleza humana, existe entonces el libre albedrío, el arrepentimiento y el retorno al buen camino. Depende de nosotros, a través de nuestros hechos, dominar esta inclinación hacia el mal.

Para Hernández-Pacheco, "la vida es al final tan hermosa, como dura en el dramático y titánico camino en que ha de superarse a sí misma. Por eso, el mal forma parte de la evolución y de la historia". 9

Hernández-Pacheco defiende que, según la idea judeo-cristiana de creación, lanaturaleza es un proyecto en desarrolloquellegaala emancipación, 
este desarrollo es liberador, que concluye en una autoconciencia autónoma.

Siguiendo con este argumento, lo que Dios crea en un momento, es en la naturaleza una evolución, es un trabajo que se hace a base de esfuerzo por parte de todos. Por ello, todo lo que nos parece definitivo, sin embargo, no lo es, el proceso aún no ha terminado. Hernández-Pacheco afirma que Dios está situado al final de este camino y sólo él sabe que, al final de él, todo saldrá bien. "La fe en Dios es también confianza en que esa esperanza no se verá defraudada". ${ }^{10}$ Dios no quiere el Holocausto definitivamente, como tampoco quiere definitivamente cualquier otra tragedia en nuestras vidas.

En la oración del Padrenuestro se expresa una esperanza en el futuro para los cristianos cuando se dice "hágase", es el deseo de que la voluntad de Dios se cumpla.

Diferentes cosas podrían haberle pasado a Jesucristo, como su naturaleza humana, también tenía la libertad de decidir, y así lo hizo. Eligió la cruz, dándose él mismo como ofrenda al Padre. Hernández-Pacheco afirma que con este sacrificio termina el tiempo de los sacrificios, y comienza uno nuevo: la era de la eucaristía, que es la época del amor y la época de dar las gracias, en la cual Satán es abatido y comienza la misericordia de Dios. Jesús es el cordero de Dios que quita el pecado del mundo, y a través de su resurrección ahora tendríamos una esperanza que nos anima a vivir con la esperanza de su segunda venida, en la que la restauración será final y eterna. Pero Jesucristo no sólo es el Mesías para los cristianos, y esto quiero dejarlo claro dado que parece que han sido los cristianos los únicos que han colocado a Jesús en el centro de su religión.

Ya sabemos que la separación entre judíos y cristiano se dio tras la muerte de Jesús, la separación no fue ni simple ni rápida, fue un proceso que tardó generaciones en producirse. Jesús fue un judío devoto toda su vida. Pero poco se conoce la existencia de los judíos mesiánicos, los cuales aceptan a Jesús como el Mesías, la diferencia fundamental con los cristianos radica en que los judíos mesiánicos consideran que Jesús (Y’shua, en hebreo) nunca vino a fundar una nueva religión. Las demás ramas del judaísmo consideran que adorar a Y'shua como el Mesías es idolatría, porque un hombre no puede ser igual a Dios, y Y'shua es un hombre, incluso un personaje histórico, pero ni es el Mesías ni tampoco un profeta. 
Hernández-Pacheco afirma que, después de la muerte de Jesucristo, quedaba la ardua tarea de vencer esa muerte, siguiendo los pasos del Padre. Jesucristo hace como hombre y como Dios a la vez lo que los hombres no pueden hacer, que es regenerar su naturaleza, la cual está débil y dañada por el pecado.

Tras la muerte, y la consiguiente resurrección, la creación ha quedado limpia de pecado. El mal sigue siendo una posibilidad, dado que el hombre posee esa libertad, de ahí la necesidad de una segunda venida del Señor.

\section{El pensamiento de Karl Barth en la obra de Javier Hernández-Pacheco}

Hernández-Pacheco hace mención en este libro, en numerosas ocasiones, del pensamiento de Karl Barth. ${ }^{11}$ A pesar de ser protestante, Hernández-Pacheco no es partidario del "libre examen", 12 nuestro autor considera que Barth "aun consiguió construir una monumental Dogmática en la que se recupera toda la reflexión sobre el Evangelio que hace la Patrística". ${ }^{13}$

Para Barth la verdad de la fe cristiana no necesita realmente de la naturaleza humana sino de la naturaleza divina, opinión compartida anteriormente por San Anselmo. La teología ha de comenzar con la Palabra de Dios, no con el hombre moderno.

Hernández-Pacheco coincide con Barth en diversos puntos. La teología liberal había rechazado la doctrina de la Trinidad, pero Barth estableció su

11 (1886-1968) Barth fue un importante teólogo protestante, considerado uno de los más importantes pensadores cristianos del siglo XX, de gran influencia en la teología contemporánea. A partir de su experiencia como pastor, se apartó de la típica teología liberal predominante, y pasó a tomar un nuevo camino teológico, llamado inicialmente "teología dialéctica", debido a su énfasis sobre la naturaleza paradójica de la verdad divina.

12 Ibíd., p. 13. Se refiere a otras doctrinas dentro del cristianismo, fuera del catolicismo. Aunque Hernández-Pacheco sí cree que Dios se revela a cada uno y que el Evangelio debe ser repensado.

13 Ibid. 372. 
doctrina en ella. Barth observó que la doctrina estaba explícitamente en las Escrituras. Barth, además, utilizó la Trinidad para explicar su teología de la Palabra/revelación. El Padre, el Padre se revela al hombre a través del Hijo y la comunicación del Espíritu. La Palabra es el Hijo y la comunicación de esa Palabra y esa Revelación es el Espíritu, este que crea en los hombres la fe. La Palabra es a la vez pronunciada y escuchada.

Barth propuso una triple división en cuanto a su doctrina de la Palabra de Dios. Por un lado, se sitúa la palabra escrita, es decir, las Sagradas Escrituras. La Biblia es el testimonio profético y apostólico de Jesucristo. Por otro lado, se sitúa la palabra predicada, es decir, el sermón de los domingos. Por encima de la palabra escrita y la palabra predicada está la Palabra de palabras, es decir, Jesucristo, él es la Palabra. Jesucristo es la revelación del Padre.

Barth, además, se oponía a la apologética, ya que todo nuestro conocimiento de Dios exclusivamente se da a través de Jesucristo. Por ello, cualquier escuela que afirme que el hombre puede llegar al conocer a Dios independientemente de Jesucristo es falsa. Esto indica que no podemos llegar a la existencia de Dios partiendo de la ética, la razón, etc., y esto se debe a que el hombre y Dios no se encuentran fuera de Jesucristo.

Estamos viendo que Barth se aleja de puntos importantes del protestantismo tradicional, lo cual es alabado por Hernández-Pacheco, ya que profundiza más en el dogma cristiano. A diferencia del protestantismo, Barth diferencia entre la revelación y las Escrituras. La revelación es el acto con el que Dios se muestra al hombre. Partiendo de eso, la Biblia no puede ser la revelación de Dios. Por lo tanto, la Biblia es el principal signo de la revelación, pero las Escrituras y la revelación no pueden estar al mismo nivel. Si la Biblia se convierte en la revelación objetiva de Dios la revelación podría llegar a materializarse. También tenemos que partir del hecho de que Barth pensaba que la Biblia tenía errores, ya que se trataba de un producto del hombre.

A todo esto, hay que añadir que, para Barth, al igual que HernándezPacheco, Dios no es el juez que recompensa a unos y castiga a otros, sino el que vela por el orden y repara lo que ha sido destruido.

La teología liberal había mezclado la evolución de la historia con el Reino de Dios, por ello, Barth decidió no añadir la historia en su teología de la Palabra. Barth si que mantuvo la distinción neokantiana entre historia 
literal e historia existencial, la historia existencial era la única esfera de la revelación. El tiempo histórico y Dios no tienen nada que ver. El tiempo cronológico lleva a la nada.

Barth se opuso al régimen nazi. Era miembro de la Federación de las Iglesias Confesantes Alemanas, esta organización se opuso a los cristianos alemanes que apoyaron al nazismo, por seguir a Hitler como si del Mesías se tratase. En 1934, escribió un ensayo titulado Nein! Antwort an Emil Brunner, en él hace una crítica de los cristianos alemanes, que pervertían el cristianismo histórico al adaptarlo a la ideología nazi, el lema de ellos era "Dios y Hitler". También en 1934, Barth redactó la Declaración de Barmen, en la cual expresaba que Jesucristo era la única palabra de Dios, y sólo a él debíamos escuchar y obedecer. Todo esto le trajo consecuencias cuando tuvo que salir de Alemania tras perder su puesto en la Universidad de Bonn, por negarse a jurar lealtad a Hitler.

\section{Paraíso: mito y fin último}

Hernández-Pacheco afirma que el paraíso no cuenta un hecho dado en la historia, se situaría, entonces, más cerca del mito. Hay que tener cuidado en cómo tomamos esto, ya que si desmitificamos el mito del paraíso, también podríamos decir que la resurrección es un mito. Lo cual, según nuestro autor, no deber ser categorizado de tal manera; de la resurrección de Jesucristo hay testigos, los cuales citan horas, lugares, circunstancias materiales, etc. Si Jesucristo no resucitó, entonces, todo sería una falsedad, ya que si Jesucristo no está vivo el Credo no se sustenta.

El tema del paraíso recurre a otro género literario distinto al de la resurrección, recurre al mito. Hernández-Pacheco lo compara con el mundo de las ideas de Platón. El mito no pretende engañar. Lo importante del mito es lo que significa. Cuando se comparten con una comunidad, "los mitos son entonces verdaderos". ${ }^{14}$ Platón emplea los mitos de la misma manera. Platón sabe de la utilidad del discurso y del pensamiento mítico para sus propósitos, como refuerzo de sus argumentos, el mito llega a los oyentes. Muchos de los pensadores modernos que estudian mito de la epopeya 
griega, afirman que constituye una fórmula pre-lógica de concepción de los fenómenos cósmicos y naturales. El sentido platónico del mito tiene un sentido paradigmático, es decir, es modelo de una realidad que sólo es imitación de otra eterna e inmutable. Por lo tanto, el mito separa o enlaza el mundo sensible con el mundo de las Ideas, es un mundo aún inaccesible para el hombre. El lenguaje de la Idea pura es el mito, ella es trascendente a las cosas e inmanente al alma.

Un gran aporte del pensamiento de Ricoeur ha sido hacer una hermenéutica en la que el mito es en una fuente de significado y verdad dentro de una filosofía que se opone a empezar con una verdad que ha sido puesta por ella.

Para Hernández-Pacheco, lo que narra el mito es verdadero en cuanto aquello que pretende contar. El mito abre un camino en dirección a lo inaccesible. La Biblia no es un libro científico, que pretenda demostrar hechos empíricos, lo que la Biblia pretende es mostrarnos la verdad que lleva a la salvación. Desde este punto, dónde estaba situado el paraíso, cuántas personas habían, qué tipo de árbol era, etc., carece de importancia. La relación en el tiempo es lo que importa, y este está en el origen de la historia.

El paraíso vuelve a convertirse, entonces, en el final de la historia, a donde todos ansiamos por llegar.

[...] tanto Paraíso Original como Tierra Prometida son pues culminación de la obra creadora de Dios. Y en este sentido, aunque para nosotros el uno esté al principio y la otra al final de la historia, (con una importante salvedad que luego veremos) los dos son para Dios la misma cosa. Dicho en el contexto filosófico en el que aquí nos manejamos con más comodidad: se trata en el primer caso del mundo platónico de las cosas verdaderas, de las ideas, que el alma contemplaba cabalgando en un carro alado acompañando al cortejo de los dioses (mito del carro alado en el Fedro), y en el segundo del fin del movimiento natural (que luego resultará que no lo es tanto) en el que todas las cosas se reencuentran en el hombre con su verdad al final de la historia. Este mismo paraíso aristotélico es la utopía de una definitiva emancipación de un paraíso social-humanista que Bloch sitúa en ese final como objeto de nuestra esperanza. Son, uno al 
principio y otro al final, dos nombres de la utopía, término por el que hemos de entender, no una delicuescente ensoñación desengranada de las condiciones históricas, sino el origen y la culminación de esa misma historia, en los que la humanidad superara (o superó) sus límites históricos y se reencontrará (o reencontró). Consigo mismo en la naturaleza. ${ }^{15}$

Bloch pensaba que el universo está pasando por una transición, desde su causa primordial (Urgrund) hasta su objetivo final (Endziel); esta transición se efectúa a través de una dialéctica sujeto-objeto, y él vio evidencias de esto en todos los aspectos de la cultura y de la historia del hombre.

Hernández-Pacheco afirma que: "Sólo en un mundo donde el ideal es original-mente más real que su desfiguración histórica, puede el hombre pre-tender alcanzar una plenitud que no sea la definitivamente perdida" ${ }^{16}$

El paraíso es, entonces, el objetivo de la creación de Dios, la perfección a la que uno quiere llegar, es el salir a la luz. Al más puro estilo platónico, los hombres que salen de la caverna y ven la luz por primera vez quedan cegados, esos hombres que se han librado de las cadenas y han salido a la luz, caminan hacia la razón y el conocimiento. Ese salir a la luz, disipar las tinieblas de la ignorancia por la luz de la razón, tan apreciado por los filósofos ilustrados.

El paraíso es, no el principio, ni el final, sino el interior del mundo, como lo que Dios comprende mientras mira y lo bendice, y que a veces nosotros, quizás por un mágico instante, vislumbramos, allí donde ese mundo se nos presenta como fantástico. ${ }^{17}$

\section{$6 \cdot$ Conclusión}

Quiero terminar con unas palabras de Hernández-Pacheco, Y se va acercando el momento en que he de presentarme ante Dios, y tendré que justificar en el juicio definitivo lo que a lo 
largo de todos estos años vengo diciendo de Él. Y este ajuste de cuentas entre lo que pienso y lo que creo (que no es para mí una ocurrencia personal sino fe compartida con la Iglesia) es algo que quiero, por así decir, dejar preparado. No sea que tenga que revisar algunas cosas. $Y$ entre nosotros que nos dedicamos a la filosofía, uno no se aclara a sí mismo si no intenta explicar a los demás lo que piensa, a ser posible, en mi caso, por escrito. Esto es lo que me gustaría hacer aquí. ${ }^{18}$

Y, en mi opinión, lo dejó muy bien explicado. Al igual que se preguntó Josef Pieper: ¿cómo es posible una filosofía cristiana?, creo que en este libro Hernández-Pacheco lo deja claro: ¿cómo no es posible una filosofía cristiana?. "Pero la filosofía no es la repetición mecánica de un discurso aprendido, sino un lenguaje que tiene que llegar a cada uno de los sujetos como algo en cierta medida comprensible" ${ }^{19}$ La filosofía no es una disciplina, sino una actividad, que debe rechazar y superar las concepciones unilaterales.

\section{7 • Bibliografía}

Arendt, Hannah. Eichmann en Jerusalén. Un Estudio sobre la Banalidad del Mal, Barcelona: Lumen, 1999.

Arendt, Hannah. Escritos Judíos, Barcelona: Magnum, 2009.

Arendt, Hannah. Los Orígenes del Totalitarismo, vol. I, II, III, Madrid: Alianza, 2009.

Barth, Karl (1994). Church Dogmatics. Louisville: Westminster John Knox Press.

Barth, Karl. Dogmatics in Outline. London: SCM, 2001.

Barth, Karl. Introducción a la Teología Evangélica. Salamanca: Sígueme, 2006.

Bloch, Ernst. Atheism in Christianity: The Religion of the Exodus and Kingdom. London: Verso, 2009.

Bloch, Ernst. The Spirit of Utopia. Stanford: Stanford University Press, 2000.

Hernández-Pacheco, Javier. ¿Alguien Entiende a Dios?. Reflexiones Sobre el Catecismo de un Profesor de Filosofía. Madrid: Sekotia, 2017.

18 Ibid. 13.

19 Ibid. 12-13. 
Hernández-Pacheco, Javier. Corrientes Actuales de la Filosofía (II). Madrid: Tecnos, 1992.

Hernández-Pacheco, Javier. Los Límites de la Razón. Madrid: Tecnos, 1992.

Hernández-Pacheco, Javier. Usted Primero. Filosofía de las Buenas Maneras. Madrid: Marova, 2019.

Holy Bible. Kansas: Catholic Bible Publishers, 1991.

Pieper, Josef . Faith, Hope, Love. San Francisco: Ignatius Press, 1997.

Pieper, Josef. On Hope. San Francisco: Ignatius Press, 2011.

Pieper, Josef. Leisure: The Basis of Culture. San Francisco: Ignatius Press, 2009. Platón. Republic. London: Phaidon Press, 2004.

Ricoeur, Paul. From Text to Action. Evanston: Northwestern University Press, 1991.

RICOEUR, Paul (2007). History and Truth. Evanston: Northwestern University Press.

Ricoeur, Paul. The Conflict of Interpretations. Evanston: Northwestern University Press, 1974.

Tanakh. New York: Jewish Publication Sociaty, 1985.

Telushkin, Rabbi Joseph. Jewish Literacy. New York: Haper Collins Publishers, 1991. 


\section{Thémata. \\ Revista de Filosofía}

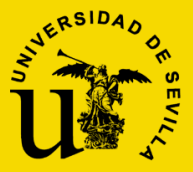

